(2) Open Access Full Text Article

\title{
Hallermann-Streiff syndrome with severe bilateral enophthalmos and radiological evidence of silent brain syndrome: a new congenital silent brain syndrome?
}

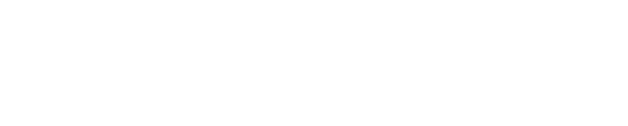

Paolo Nuccil

Carlo de Conciliis ${ }^{2}$

Matteo Sacchi'

Massimiliano Serafino'

'Eye Clinic, San Giuseppe Hospital, University of Milan, ${ }^{2}$ Eye Clinic, Istituto Auxologico Italiano, Milan, Italy
Correspondence: Matteo Sacchi Eye Clinic, San Giuseppe Hospital, University of Milan,Via San Vittore 12, Milan 20123, Italy

$\mathrm{Tel}+390250323150$

Fax +390250323150

Email teosacchi@excite.it
Background: We present the first case of a congenital form of silent brain syndrome (SBS) in a young patient affected by Hallermann-Streiff syndrome (HSS) and the surgical management of the associated eyelid anomalies.

Methods: HSS signs were evaluated according to the Francois criteria. Orbital computed tomography (CT) and genetic analysis were performed. An upper eyelid retractor-free recession was performed. Follow-up visits were performed at day 1, weeks 1 and 3, and months 3, 6, 9 (for both eyes), and 12 (for left eye) after surgery.

Results: The patient exhibited six of the seven signs of HSS. Orbital CT showed bilateral enophthalmos and upward bowing of the orbital roof with air entrapment under the upper eyelid as previously described for SBS. Genetic analysis showed a $2 q$ polymorphism. During follow-up, the cornea showed absence of epithelial damage and the upper eyelids were lowered symmetrically, with a regular contour.

Conclusion: Our HSS patient shares features with SBS. We postulate that SBS could include more than one pattern, ie, an acquired form following ventriculoperitoneal shunting and this newly reported congenital form in our HSS patient in whom typical syndromic skull anomalies led to this condition. The surgical treatment has been effective in restoring an appropriate lid level, with good globe apposition and a good cosmetic result.

Keywords: Hallermann-Streiff syndrome, silent brain syndrome, upper eyelid entropion

\section{Introduction}

This case report describes the ophthalmologic features of a four-year-old child with Hallermann-Streiff syndrome (HSS) presenting also with a condition very similar to the so-called "silent brain syndrome" (SBS), with severe bilateral enophthalmos, bridging of all the tarsal plates off the ocular surface, and secondary upper eyelid entropion, retraction, and lagophthalmos. We describe the clinical appearance of the patient and the surgical management of the associated upper eyelid retraction and entropion. To our knowledge, this is the first report of a congenital SBS and surgical management of the upper eyelid entropion in a young patient affected by HSS.

\section{Case report}

The child was delivered at 36 weeks because of fetal distress occurring as a result of a lack of amniotic fluid. The parents' marriage was nonconsanguineous. The child was hospitalized for 36 days in the neonatal intensive care unit. General examination of the 
head and the face reveled the following signs: abnormalities of the skull with hypoplastic mandible, micrognathia, frontal bossing; a beak-shaped nose; abnormalities of the eye, with microblepharon, flat orbits, and enophthalmos; atrophy of the skin over the nose and the eyelids associated with hypotrichosis of the scalp; and dental anomalies including malocclusion, caries, and malformed teeth. The cycloplegic refractive error was +1.50 in both eyes. A diagnosis of HSS was made on the basis of the criteria reported by Francois. ${ }^{1}$

Ocular adnexal examination revealed a microblepharon with bilateral upper eyelid retraction, entropion, and bridging of the tarsal plates off the ocular surface. Preoperatively, the distance between the upper lid and the apex of the corneal limbus was $6 \mathrm{~mm}$. There was also marked orbital fat atrophy with relative enophthalmos. The upper fornix was unusually deep (Figure 1A) with copious accumulation of thick mucopurulent discharge (Figure 1B).

Because of epiphora, nasolacrimal duct probing was performed. The probing revealed bilateral congenital nasolacrimal duct atresia, as reported in other craniofacial malformations. The upper eyelid retraction, lagophthalmos, and inverted eyelashes caused a severe traumatic keratopathy with serious epithelial corneal damage and copious filamentary secretion. Corneal involvement produced pain, burning, foreign body sensation, tearing, blurred vision, and severe photophobia. Visual acuity was 20/100 and 20/200 in the right and left eye, respectively. Ocular motility was within normal limits. Mental development was reported
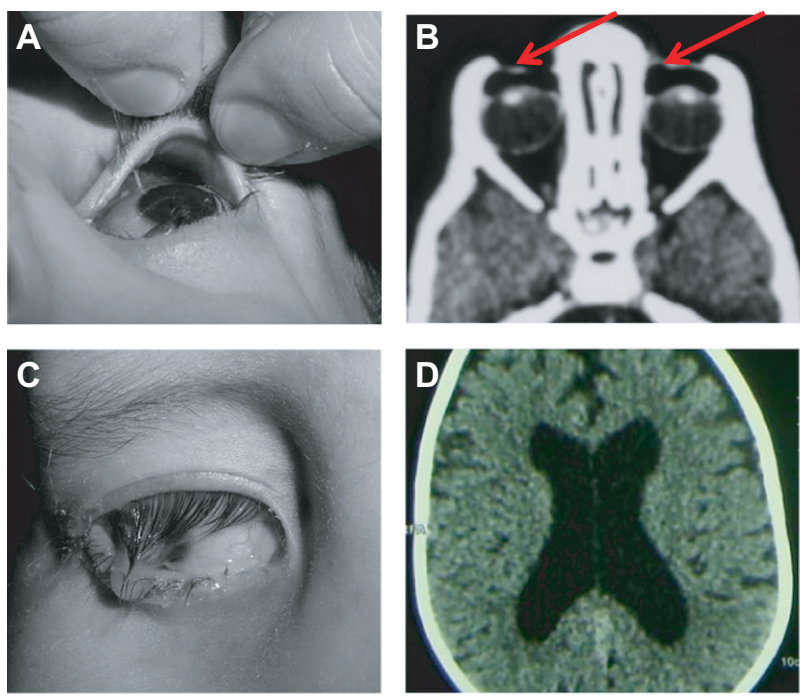

Figure I (A) Unusually deep upper fornix. (B) Orbital computed tomography showing bilateral enophthalmos and upward bowing of orbital roof with air entrapment (red arrows) under upper eyelid. (C) Copious amounts of mucopurulent discharge from upper fornix. (D) Cerebral computed tomography showing mild enlargement of lateral ventricles. to be normal. Genetic analysis, and an orbital and cerebral computed tomography (CT) scan were performed before surgery.

Transnasal fiberscope examination of the upper airway was performed before surgery in order to investigate the upper airway anatomy. The examination revealed nasal cavity restriction, macroglossia, and epiglottic hypoplasia. General anesthesia and intubation were uneventful. A recession and extirpation of the levator aponeurosis and Muller muscle were performed through an anterior lid crease approach.

The eye most seriously affected by corneal damage was treated first. The second eye was treated after 3 months (to properly assess the results of the first surgery, and because the mother was pregnant with a second baby and delivery was scheduled 1 month after the first surgery). The incision was made at the pre-existing upper lid crease, about $5 \mathrm{~mm}$ from the eyelid margin. Dissection was carried out in the sub-orbicularis oculi muscle plane downward until the tarsal plate was exposed, and upward to the orbital septum which was opened to expose the levator aponeurosis and to release it completely from the septum itself. The levator aponeurosis and Muller muscle were dissected free from the upper tarsal margin and from the underlying conjunctiva for several millimeters almost up to the upper fornix. Care was taken to leave the conjunctiva intact. The free edge of the retractor complex was allowed to retract freely and then cut for about $2 \mathrm{~mm}$ in order to avoid reattachment on the tarsal plate. Skin closure was performed with three interrupted 6-0 Vicryl absorbable sutures. The surgery lasted 45 minutes. The surgery and general anesthesia were uneventful.

Follow-up visits were performed at day 1, weeks 1 and 3, and months 3, 6, 9 (for both eyes), and 12 (for left eye) after surgery to monitor the condition of the cornea, eyelid, and eyelash position, as well as the patient's symptoms after surgery.

\section{Results}

According to the criteria described by Francois, ${ }^{1}$ our patient had six of the seven signs of HSS (bird-like facies, abnormal dentition, hypotrichosis, atrophy of skin especially on the nose, bilateral microphthalmia, and proportionate short stature). Other authors have reported six main signs and supplementary findings as criteria for diagnosis of HSS. ${ }^{2}$ According to these criteria, our patient had five of the six signs of the syndrome. On the basis of these findings, we opted for a diagnosis of HSS.

Orbital CT showed bilateral enophthalmos and upward bowing of the orbital roof, with air entrapment under the 
upper eyelid (Figure 1B) as previously described for SDS by Bernardini et al. ${ }^{3}$ Cerebral CT showed a mild enlargement of the lateral ventricles without signs of intracranial hypertension. Genetic analysis showed a 2q polymorphism in the proband and the parents proved to be carriers of the same polymorphism. They were clinically normal, without apparent phenotypical anomalies.

At the 9-month (for both eyes) and 12-month (for left eye) follow-up visits, the cornea showed complete absence of epithelial damage, as evidenced by a negative fluorescein stain. The upper eyelid were lowered symmetrically with a regular contour, and the eyelashes were not longer touching the cornea (Figure 2B). Visual acuity improved to $20 / 20$ in both eyes. The corneal epithelial damage-related symptoms of pain, foreign body sensation, and photophobia had completely disappeared.

\section{Discussion}

\section{Hallermann-Streiff syndrome}

HSS is a rare genetic syndrome primarily characterized by head and facial abnormalities. The first report of HSS was published by Aubry in 1893 (as cited in Warkany). ${ }^{4} \mathrm{HSS}$ was eventually described by Hallermann in 1948 and by Streiff in 1950. More than 150 cases have been published up to 1982..$^{5}$ In 1958, Francois reported seven essential signs for diagnosis of HSS. ${ }^{1}$ The appearance of HSS probably results

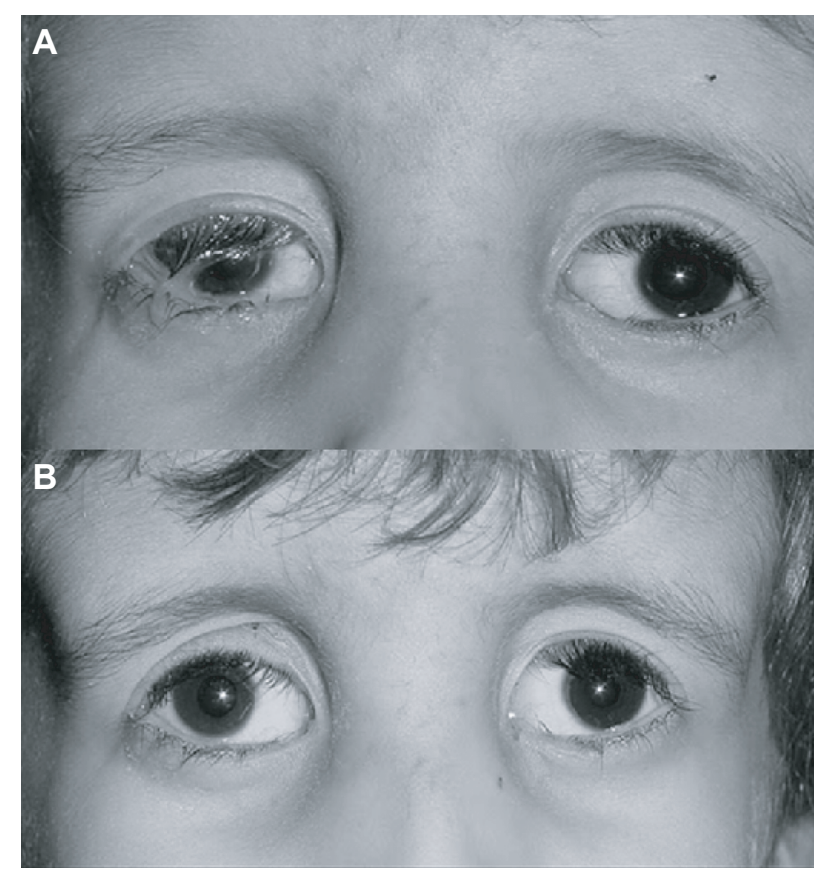

Figure 2 (A) Preoperative and postoperative features in the right and in the left eye, respectively, at 3 months. (B) Postoperative features in the right and in the left eye respectively at 9 and 12 months. from an asymmetric second branchial arch defect arising during the fifth or sixth gestational week. ${ }^{6}$ Genetic analysis in our patient showed a common and not significant or specific polymorphism. Other genetic anomalies have been reported previously. A report in 1980 described an elongation of one of the arms of chromosome 10. ${ }^{7}$ Pugliese et al found a $16 \mathrm{qh}+$ polymorphism in an infant with HSS. ${ }^{8}$ Pizzuti et al reported genetic analysis of a patient with an overlapping HSS/oculodentodigital dysplasia phenotype showing a homozygous GJA1 mutation, ${ }^{9}$ while analysis of a patient with a full-blown HSS phenotype did not show any mutation in the GJA1 coding sequences. The author concluded that HSS can be a genetically heterogeneous disorder.

Respiratory suppression is one of the most serious complications in HSS patients, and problems with intubation and tracheotomy are described due to upper airway obstruction, glossoptosis, micrognathia, and abnormal glottis closure. Early death due to respiratory complications is known to occur in these patients. ${ }^{10}$ Orotracheal intubation difficulty, upper airway obstruction, and respiratory depression during general anesthesia has been described in the literature in patients with HSS. ${ }^{11-13}$

\section{Upper eyelid retraction}

Our patient showed bilateral congenital upper eyelid retraction with inverted eyelashes and entropion. This is the first report of this condition in a HSS patient. Upper eyelid retraction is an ophthalmological condition most frequently associated with Graves ophthalmopathy. ${ }^{14}$ Other published reports describe upper eyelid retraction associated with blow-out fracture of the orbit, ${ }^{15-17}$ following periorbital contusion without fracture, ${ }^{18}$ after ocular surgery, ${ }^{19}$ in patients with neurogenic disease $^{20}$ and associated with contralateral blepharoptosis. ${ }^{21}$ Cruz et al reported two cases of unilateral upper eyelid cicatricial retraction in patients with encephalocraniocutaneous lipomatosis. ${ }^{22}$ Bartley recently proposed a classification system for eyelid retraction based on three categories, ie, neurogenic, myogenic, and mechanical..$^{20}$

Few data are published in the literature about upper eyelid retraction in children. The etiologies known for this condition in children are described by Stout et al, who reported 11 cases of unilateral and five cases of bilateral eyelid retraction. The causes of monolateral cases were congenital aberrant innervation of the third nerve, levator fibrosis, hemangioma, hyperthyroidism, craniosynostosis, and Down syndrome. Bilateral eyelid retraction was associated with either hyperthyroidism or bilateral optic nerve anomalies and vertical nystagmus. ${ }^{23}$ Spierer and Bourla reported four cases 
of congenital unilateral and bilateral upper eyelid retraction without other ocular or systemic pathology. ${ }^{24}$ In our patient, the upper eyelid retraction and entropion was probably related to the dysfunctional relationship between eyelid and globe. The globe has a more posterior position due to orbital fat atrophy, microphthalmos, and enlargement of the orbit due to the upward bowing of the orbital roof and does not properly support the upper eyelid edge.

\section{Silent brain syndrome}

An acquired form of bilateral enophthalmos has been described in young patients whose only systemic association was a congenital hydrocephalus treated with a ventriculoperitoneal shunt. ${ }^{25}$ The upper eyelids show poor globe apposition owing to the recessed position of the globe, as in our patient. Orbital CT scan showed marked enophthalmos and some air trapped between the upper eyelid and globe. Cerebral CT showed dilated ventricles. These CT findings were also seen in our patient.

Most recently, Bernardini et al reported two cases of gross acquired bilateral enophthalmos following childhood hydrocephalus treated by ventriculoperitoneal shunting. ${ }^{3}$ The patients had enophthalmos with bridging of the eyelid away from the ocular surface, and CT scans showed marked upward bowing of the orbital roof and air entrapment under the upper eyelids. The mechanism speculated for this condition is a sudden reduction of raised intracranial pressure causing an implosion of the only thin cranial bone, ie, the orbital roof. This upward bowing of the roof leads to a progressive enophthalmos. The authors referred to this condition as SBS.

\section{Conclusion}

Our HSS patient had features of SBS, showing bilateral congenital enophthalmos with poor apposition between the upper eyelid and globe, upper eyelid retraction with entropion, and an unusually deep upper fornix with copious discharge. A mild form of hydrocephalus without signs of intracranial hypertension was present, consistent with previous reports of this condition. We postulate that this disorder could be a clinical entity including several clinical patterns, ie, the acquired form following ventriculoperitoneal shunting, where remodeling of the cranial bone seems to lead to the characteristic clinical and radiological changes, and this newly reported congenital form in our HSS patient, in whom typical syndromic skull and orbit anomalies (flat orbits, enophthalmos, and microphthalmos) led to the condition. In its congenital form, it is not clear if the relative enophthalmos is caused by the marked bony anomalies or if they are caused by relative intracranial hypotension during fetal development, similar to what happens in the acquired post ventriculoperitoneal shunt variant. Surgical treatment of the severe keratopathy caused by the upper eyelid anomalies and inverted eyelashes has so far been very effective in restoring an appropriate lid level with good globe apposition, thus completely resolving the underlying corneal problems with a good cosmetic result in this patient with HSS and a congenital form of SBS.

\section{Disclosure}

The authors report no conflicts of interest in this work.

\section{References}

1. Francois J. A new syndrome; dyscephalia with bird face and dental anomalies, nanism, hypotrichosis, cutaneous atrophy, microphthalmia, and congenital cataract. Arch Ophthalmol. 1958;60:842-862.

2. Wiedemann HR, Kunze J. Clinical Syndromes. London, UK: Mosby-Wolfe; 1997.

3. Bernardini FP, Rose GE, Cruz AA, et al. Gross enophthalmos after cerebrospinal fluid shunting for childhood hydrocephalus: The "silent brain syndrome”. Ophthal Plast Reconstr Surg. 2009;25:434-436.

4. Warkany J. Congenital Malformations Notes and Comments. Chicago, IL: Year Book Medical Publications; 1971.

5. Wiedemann HR. Hallermann-Streiff syndrome. In: Wiedemann HR, Kunze J, Dibbern H, editors. An Atlas of Clinical Syndromes, a Visual Aid to Diagnosis. 2nd ed. St Louis, MO: Mosby; 1992.

6. Mirshekari A, Safar F. Hallermann-Streiff syndrome: a case review. Clin Exp Dermatol. 2004;29:477-479.

7. Schanzlin DJ, Goldberg DB, Brown SI. Hallermann-Streiff syndrome associated with sclerocornea, aniridia, and a chromosomal abnormality. Am J Ophthalmol. 1980;90:411-415.

8. Pugliese GF, La Torre G, La Torre F. Chromosomal and clinical features in an infant with Hallermann-Streiff syndrome. Arch Dis Child. 1997;77:183.

9. Pizzuti A, Flex E, Mingarelli R, et al. A homozygous GJA1 gene mutation causes a Hallermann-Streiff/ODDD spectrum phenotype. Hum Mutat. 2004;23:286.

10. Jones KL. Smith's Recognizable Patterns of Human Malformations. 4th ed. Philadelphia, PA: WB Saunders; 1988.

11. Kim S, Nishizawa M, Kasama S, et al. Management of difficult airway during induction of anesthesia in a patient with Hallermann-Streiff syndrome. Masui. 1998;47:865-867. Japanese.

12. Robinow M. Respiratory obstruction and cor pulmonale in the Hallermann-Streiff syndrome. Am J Med Genet. 1991;41:515-516.

13. Wong DT, Woo JA, Arora G. Lighted stylet-guided intubation via the intubating laryngeal airway in a patient with Hallermann-Streiff syndrome. Can J Anaesth. 2009;56:147-150.

14. Hwang JM, Kim WB. Etiology of eyelid retraction in Koreans. J Korean Ophthalmol Soc. 1998;39:1069-1076.

15. Putterman AM, Urist MJ. Upper eyelid retraction after blowout fracture. Arch Ophthalmol. 1976;94:112-116.

16. Conway ST. Lid retraction following blow-out fracture of the orbit. Ophthalmic Surg. 1988;19:279-281.

17. Hatt M. Post-traumatic upper eyelid retraction. Klin Monbl Augenheilkd. 1985;186:217-219; German.

18. Kwon SI, Kim YJ. Upper eyelid retraction after periorbital trauma. Korean J Ophthalmol. 2008;22:255-258.

19. Mauriello JA Jr, Palydowycz SB. Upper eyelid retraction after retinal detachment repair. Ophthalmic Surg. 1993;24:694-697.

20. Bartley GB. The differential diagnosis and classification of eyelid retraction. Ophthalmology. 1996;103:168-176. 
21. Meyer DR, Wobig JL. Detection of contralateral eyelid retraction associated with blepharoptosis. Ophthalmology. 1992;99:366-375.

22. Cruz AA, Schirmbeck T, Pina-Neto JM, et al. Cicatricial upper eyelid retraction in encephalocraniocutaneous lipomatosis: a report of two cases and review of literature. Ophthal Plast Reconstr Surg. 2002;18:151-155.

23. Stout AU, Borchert M. Etiology of eyelid retraction in children: a retrospective study. J Pediatr Ophthalmol Strabismus. 1993;30: 96-99.
24. Spierer A, Bourla N. Primary congenital upper eyelid retraction in infants and children. Ophthal Plast Reconstr Surg. 2004;20:246-248.

25. Meyer DR, Jeffrey AN, Nancy JN, et al. Bilateral enophthalmos associated with hydrocephalus and ventriculoperitoneal shunting. Arch Ophthalmol. 1996;114:1206-1209.

\section{Publish your work in this journal}

Clinical Ophthalmology is an international, peer-reviewed journal covering all subspecialties within ophthalmology. Key topics include: Optometry; Visual science; Pharmacology and drug therapy in eye diseases; Basic Sciences; Primary and Secondary eye care; Patien Safety and Quality of Care Improvements. This journal is indexed on

Submit your manuscript here: http://www.dovepress.com/clinical-ophthalmology-journal

\section{Dovepress}

PubMed Central and CAS, and is the official journal of The Society of Clinical Ophthalmology (SCO). The manuscript management system is completely online and includes a very quick and fair peer-review system, which is all easy to use. Visit http://www.dovepress.com/ testimonials.php to read real quotes from published authors. 